\title{
INDICADORES DE GESTÃO DO FLUXO EDITORIAL DOS PERIÓDICOS CIENTÍFICOS: UMA REFLEXÃO TEÓRICO-METODOLÓGICA
}

\author{
Daniela Spudeit ${ }^{\mathrm{i}}$ \\ Elisabete Werlang ${ }^{\text {ii }}$ \\ Nadi Helena Presser ${ }^{\text {ii }}$
}

\begin{abstract}
Resumo: Este artigo apresenta uma reflexão teórico-metodológica da construção de indicadores de gestão do fluxo editorial de um periódico científico. O objeto empírico desta pesquisa estendeu sua ação na esfera de atuação da revista científica do Senac/SC. Devido à sua natureza participativa e prática, o estudo foi desenvolvido pela equipe editorial seguindo os pressupostos metodológicos da pesquisa-ação e da pesquisa exploratória e teve como fonte primária de informações e evidências o Documento de Área de Administração, Ciências Contábeis e Turismo, triênio 2007-2009. Os indicadores propostos descrevem o que e em quais parâmetros avaliar o periódico, na perspectiva de acompanhar o processo de implantação e manutenção deste e de garantir o cumprimento das diretrizes e dos padrões de qualidade estabelecidos pelas instâncias reguladoras.
\end{abstract}

Palavras-chave: Comunicação científica. Revista científica. Indicadores. Fluxo editorial. Senac.

\section{INDICATORS FOR THE MANEGEMENT OF THE EDITORIAL FLOW IN SCIENTIFIC PERIODICALS: A THEORETICAL AND METHODOLOGICAL REFLECTION}

\begin{abstract}
This article presents a theoretical and methodological reflection for the establishment of indicators for the editorial flow of a scientific periodical. The empirical object of the research was the sphere of action of Senac's scientific magazine. Due to its practical and participative nature of this study, it was carried out by the editorial staff of the magazine following the methodological assumptions of action-research and exploratory research. The document of administration, accounting sciences and tourism concerning the period 2007-2009 represented the primary source of information and evidences for this study. The proposed indicators describe what evaluate in the periodical and in which parameters, aiming to examine the process of the periodical implementation and maintenance, and also to assure the execution of the directions and the quality standards established by the regulating spheres.
\end{abstract}

Keywords: Scientific Communication. Scientific magazine. Indicators. Editorial Flow. Senac.

\footnotetext{
${ }^{\mathrm{i}}$ Universidade do Estado de Santa Catarina - danielaspudeit@gmail.com

ii Senac/SC - betewerlang@gmail.com

iii Universidade Federal de Pernambuco - nadihelena@uol.com.br 102 


\section{INTRODUÇÃO}

Os periódicos científicos constituem atualmente o principal instrumento de comunicação científica, possuindo as funções de disseminação e de recuperação do conhecimento produzido, propiciando a visibilidade da instituição, do periódico, de seus autores e editores.

As universidades e instituições de ensino superior possuem uma missão social frente às mudanças econômicas, políticas e tecnológicas, seja promovendo a análise e a reflexão crítica da sociedade, seja desconstruindo e construindo novos paradigmas sociais por meio das pesquisas e das publicações de seus resultados, processos estes conduzidos no âmago do ambiente acadêmico. Além disso, conforme evidenciam Ferreira e Targino (2010, p. 9),

\footnotetext{
o artigo científico converteu-se no fundamento da avaliação do pesquisador, dos programas de pesquisa e pós-graduação e do reconhecimento da excelência de produtividade e criatividade de indivíduos, grupos e redes de criação e inovação do conhecimento.
}

Nesse contexto, a ampliação do escopo de atuação com a introdução da educação superior a partir de 2003 e, atualmente, com oito faculdades de tecnologia credenciadas, impôs ao Serviço Nacional de Aprendizagem Comercial de Santa Catarina (Senac/SC) novos desafios e responsabilidades. O compromisso institucional com os padrões de qualidade requeridos na educação superior e nas suas unidades constituintes passa a exigir a criação e consolidação de programas institucionais de pesquisa e comunicação científica, com características e particularidades próprias.

Destaca-se o programa de pesquisa e extensão introduzido no Senac/SC em 2008, como estratégia de consolidação e efetivação do princípio da indissociabilidade entre ensino, pesquisa e extensão, interligados e inseridos num contexto intimamente relacionado ao objetivo primordial da educação superior tecnológica.

Outra iniciativa foi a institucionalização do Programa de Iniciação Científica (PIC) no Senac/SC em meados de 2008, definindo diretrizes e assessorando a comunidade acadêmica no planejamento, na implantação e no monitoramento das suas atividades de pesquisa. Para incentivar a participação dos alunos, foi criada a Bolsa PICSenac, com critérios específicos para selecionar alunos bolsistas para se engajarem na iniciação científica, e foi estabelecida carga horária remunerada aos docentes interessados no desenvolvimento de trabalhos, envolvidos em grupos de pesquisas. A criação desse programa foi um indicativo do valor dado à ciência no interior da instituição, despertando a vocação científica e incentivando a participação de discentes e docentes na prática da produção intelectual. 
Nesse contexto, a criação de uma revista científica foi o caminho natural que o Senac/SC encontrou para a divulgação da produção científica de seus discentes, docentes e de pesquisadores externos. Foi a consolidação de um projeto que contou com o apoio da direção regional, mantenedora das faculdades de tecnologia no estado, no fornecimento dos recursos necessários para viabilizar a publicação da revista. Contou também com a participação efetiva das faculdades na constituição da equipe editorial, destacando-se a Faculdade de Florianópolis, uma das mentoras do projeto.

Assim, em 2011 é lançada a primeira edição da NAVUS $^{3}$ - Revista de Gestão e Tecnologia do Senac/SC, que tem como principal objetivo promover o estudo e a reflexão crítica no campo da gestão e da tecnologia e o desafio de consolidar uma publicação de referência no meio acadêmico-científico e no meio empresarial, viabilizada eletronicamente pelo Sistema Eletrônico de Editoração de Revistas (SEER), customizado pelo Instituto Brasileiro de Informação em Ciência e Tecnologia (IBICT).

$\mathrm{Na}$ edição de uma revista científica, entretanto, é condição essencial que sejam seguidas normas e procedimentos padrões estabelecidos pelas instâncias reguladoras. É sabido que o processo de produção do conhecimento, desde a concepção do projeto, do desenvolvimento da pesquisa, da construção da comunicação e divulgação dos resultados, exige um esforço de gestão que, se não empreendido, compromete sua qualidade, quer seja pelo não atendimento dos requisitos recomendados, quer pelo alto custo para sua sustentação, ou por outros desafios que precisam ser gerenciados.

Com base nas particularidades apresentadas acima, caracteriza-se este estudo como uma reflexão teórico-metodológica de construção de indicadores de gestão do fluxo editorial de um periódico científico. Os indicadores, pela sua objetividade e precisão, assumem um papel de destaque, mesmo que não constituam a última instância a ser considerada. A avaliação do desempenho, na gestão do fluxo editorial, representa um processo de autocrítica e de acompanhamento das atividades, das ações e decisões que são tomadas na consolidação do periódico.

O objeto empírico desta pesquisa estendeu sua ação na esfera de atuação da revista científica do Senac/SC, abrangendo desde a concepção e formulação dos indicadores, até sua validação em nível da equipe editorial e homologação em nível dos gestores da instituição.

\footnotetext{
${ }^{3}$ Do latin navare, návitas, navita, nauta (subst. masc. que significa marinheiro, navegador); do grego naving (que é próprio do piloto ou apto para ser piloto); NAVUS significa aquele que navega no universo do conhecimento. 


\section{PROCEDIMENTOS METODOLÓGICOS}

Esta pesquisa procurou respostas para as questões suscitadas na fase de concepção da revista NAVUS e devido à sua natureza participativa e prática, o método da pesquisa-ação se mostrou adequado para o desenvolvimento de um esforço planejado da equipe editorial no trabalho de construção coletiva de um conjunto de indicadores. Um dos principais objetivos da pesquisa-ação, evidenciado por Thiollent (1985, p. 8), é “dar aos pesquisadores e grupos participantes os meios de se tornarem capazes de responder com maior eficiência aos problemas da situação em que vivem, em particular sob forma de diretrizes de ação transformadora".

Considerando a natureza do trabalho, a pesquisa-ação foi combinada com a abordagem da pesquisa exploratória (GIL, 2007) que, na sua perspectiva, presume um processo de descoberta, como um instrumento que vai conduzindo as conclusões sobre o objeto de observação.

A coleta dos dados consistiu de uma análise documental (MARTINS; THEÓPHILO, 2009) do Documento de Área de Administração, Ciências Contábeis e Turismo, triênio 20072009, para fins de cumprir os requisitos mínimos para um periódico ser avaliado nos estratos de B5 a A1, bem como as diretrizes de avaliação e classificação expressas para Qualis de periódicos, aprovadas pela Comissão de Área.

A análise e o tratamento dos dados consistiram na tarefa de traduzir, em indicadores de desempenho, os requisitos da área e das instâncias reguladoras, e estabelecer valores de referência permitindo o monitoramento dos resultados, na perspectiva de consolidar a NAVUS como um periódico de nível internacional, ao longo do tempo.

O processo integrou conhecimentos relativos aos indicadores de desempenho de natureza estocástica, observando as características a priori e desejáveis que qualquer indicador deve necessariamente exibir, segundo Trzesniak (1998), tais como: relevância, gradação de intensidade, univocidade, padronização e rastreabilidade. As características desejáveis dizem respeito à cobertura, portabilidade e invariância de escala. 


\section{FUNDAMENTAÇÃO TEÓRICA DO SISTEMA DE INDICADORES}

Ao longo de sua história, os periódicos científicos vêm apresentando contribuições fundamentais na comunicação científica, pois facilitam a organização e disseminação do conhecimento.

\footnotetext{
Desde que começaram a ser publicadas, no século XVII, as revistas científicas passaram a desempenhar importante papel no processo de comunicação da ciência. Surgiram como uma evolução do sistema particular e privado de comunicação que era feito por meio de cartas entre os investigadores e das atas ou memórias das reuniões científicas (STUMPF, 1996).
}

Como disseminador da informação, além de despertar interesse e fomentar discussões sobre temas veiculados, o periódico científico fornece informações mais filtradas e com assuntos específicos de uma determinada área.

Com os avanços tecnológicos ocorridos no século XX e o advento das tecnologias da informação, o periódico científico obtém um novo suporte de divulgação, os sistemas eletrônicos, que, com a popularização da internet, passam a ser incorporados como um novo meio de acesso à informação. As constantes mudanças tecnológicas têm exigido dos periódicos eletrônicos melhorias em sua usabilidade e legibilidade para atender à demanda de um público especializado e com necessidade de acesso à informação de uma forma rápida e precisa.

É no periódico científico eletrônico que o conhecimento pode ser disseminado de forma mais atualizada e confiável, em virtude da periodicidade e dos rigorosos processos de revisão pelos pares. O sistema de comunicação científica é um elemento estruturador vital da comunidade científica (MUELLER, 2003). Dessa forma, os periódicos científicos são os veículos disseminadores da produção científica em determinada área do conhecimento, e são as áreas que se organizam e se estruturam para criar, manter, disseminar e preservar suas informações, promovendo a geração do capital científico cumulativo.

A comunicação científica assegura a credibilidade e visibilidade da produção e o progresso da ciência, podendo ser definida, segundo Barbalho (2005, p. 125), como “a promoção de intercâmbio de informações entre membros de determinada comunidade, a qual divulga os resultados de pesquisas efetivamente de acordo com regras definidas e controladas pelo contexto onde está inserida".

$\mathrm{Na}$ edição de uma revista científica é comum seguir normas e padrões nacionais e internacionais. Conforme Fachin e Hillesheim (2006, p. 101), “o uso destes padrões favorece 
e simplifica a recuperação das informações contidas nos periódicos científicos, como também sua organização e preservação".

Ao refletir sobre a qualidade das revistas, Fischman (2010) advoga que pausas e interrupções na periodicidade das revistas científicas ocorrem por diversos motivos, entre os mais expressivos:

- Problemas com o financiamento, porque dependem do apoio das instituições, das fundações de apoio à pesquisa, do investimento dos governos.

- Qualidade - na América Latina, os grandes problemas são os desvios gramaticais, metodológicos e de conteúdo.

- Plágio - outro grande problema, pois a maioria das revistas não utiliza um sistema específico para detectar isso.

- Potencial contribuição (responsabilidade) dos comitês editoriais e dos avaliadores para "educar" (os autores) acerca dos padrões e metodologias para a publicação de artigos (FISCHMAN, 2010).

Os critérios de medição e avaliação da veiculação científica visam assegurar a originalidade, legitimidade, credibilidade, usabilidade e visibilidade da produção científica de um periódico e evidenciam a importância da gestão do fluxo editorial, cuja abrangência ou escopo são definidos pelo gestor, em vistas de seu propósito de observação e controle.

Em um sistema de gestão, um indicador é uma representação quantificável das características de produtos e processos, utilizados para manutenção e/ou melhoria da qualidade e do desempenho de um produto, serviço ou processo, ao longo do tempo (TAKASHINA, 1999).

Um aspecto relevante diz respeito às relações de causa e efeito dos indicadores, relativas às suas características determinísticas ou estocásticas.

Pertencem à categoria das relações determinísticas aquelas em que causa e efeito estão ligadas diretamente: a presença (ou uma variação) da primeira necessariamente implica o surgimento (ou uma alteração) no último, freqüentemente obedecendo a uma lei matemática conhecida (pelo menos, essa é uma condição que contribui muito para o sucesso dos indicadores envolvidos). Já no caso das estocásticas, a vinculação entre causa e efeito torna-se indireta, a presença (ou uma variação) da primeira reflete-se não no efeito, mas na probabilidade de ele surgir (ou se modificar) (TRZESNIAK, 1998, p. 160).

Um exemplo de relação estocástica é aquela existente entre a presença do periódico em bases de dados e a visibilidade do periódico: tal relação existe, mas não é determinística, 
no sentido de que não está assegurado que a indexação do periódico fará aumentar o seu fator de impacto. A indexação em bases de dados referendadas por determinada área do conhecimento não aumenta o índice de fator de impacto como consequência imediata e necessária, mas seguramente aumenta a probabilidade de que isso aconteça.

Muitos especialistas na área de qualidade incentivam o envolvimento de todos no esforço para a formulação de indicadores amplamente conhecidos, padronizados e facilmente compreensíveis. Paladini (2002) recomenda observar propriedades como: objetividade, clareza, precisão, viabilidade, representatividade, visualização, ajuste, unicidade, alcance e resultados. Camargo (2000), por sua vez, recomenda a formulação de indicadores motivadores, confiáveis, significativos e de interpretação universal.

Trzesniak (1998) propõe observar algumas características a priori que qualquer indicador deve necessariamente exibir:

- Relevância: o indicador deve retratar um aspecto importante do processo.

- Gradação de intensidade: o indicador deve variar suficientemente no âmbito do processo.

- Univocidade: o indicador deve retratar um aspecto único e bem definido do processo.

- Padronização: a geração do indicador deve basear-se em uma norma única, bem definida e estável no tempo.

- Rastreabilidade: os processos de apuração do indicador devem ser registrados e preservados. Pressupõe especificar o local em que os dados podem ser coletados, a metodologia de sua obtenção, bem como o período de coleta, de forma a tornar o processo bem definido.

$\mathrm{Na}$ falta de uma característica, como a univocidade, por exemplo, a análise do resultado poderá somente registrar um resultado indesejável, mas não permitir a definição de qualquer ação corretiva, uma vez que o indicador não encerra a natureza exata do que vai mal.

Trzesniak (1998) também chama a atenção para as características desejáveis dos indicadores que, quando presentes, permitem que um mesmo indicador seja aplicado a processos diversos daqueles para os quais ele foi inicialmente concebido, sem perder sua validade. As características desejáveis dizem respeito à cobertura, portabilidade e invariância de escala.

- A amplitude aumenta quando uma nova aplicação de indicador pode ser usada em processos e sistemas de natureza diferentes, porém dentro da mesma área do conhecimento na qual o indicador é usualmente empregado. 
- A portabilidade mais forte significa que o uso do indicador pode ser estendido para o estudo de processos e sistemas de outras subáreas do conhecimento.

- A invariância de escala está presente quando um indicador mantém sua validade, mesmo que o processo ou sistema estudado seja acentuadamente diferente.

Prestar atenção nessas características dos indicadores implica, segundo observações de Trzesniak (1998), evitar tomadas de decisão erradas, com sérios prejuízos morais para pessoas ou instituições, em decorrência de um excesso de confiança em números de validade não suficientemente estabelecida.

\section{FORMULAÇÃO DOS INDICADORES}

Além do respaldo de uma estrutura teórica sobre o tema, o processo de formulação dos indicadores foi precedido pela compreensão das diretrizes estabelecidas no documento de Área de Administração, Ciências Contábeis e Turismo, e exigiu um estudo da sistemática de classificação dos periódicos e da distribuição dos estratos ${ }^{4}$, bem como a identificação do papel dos stakeholders: corpo diretivo do Senac/SC, editores, comitês científicos, autores, avaliadores e leitores potenciais.

Para atingir os níveis de qualidade do periódico científico, uma ampla questão deveria ser respondida pela equipe editorial para elaborar o projeto da revista científica do Senac/SC, a saber:

Como monitorar o fluxo editorial do periódico científico na perspectiva de consolidar uma publicação de referência no meio acadêmico-científico e no meio empresarial no campo da gestão e tecnologia?

Tal questão suscitou em favor da concepção de um modelo de gestão do fluxo editorial orientado por indicadores de desempenho, entendidos como medidas que monitoram o resultado do processo, visando garantir o cumprimento das diretrizes e dos padrões de

\footnotetext{
${ }^{4}$ A CAPES é o órgão de regulação responsável pela institucionalização do Qualis, o conjunto de procedimentos utilizados para estratificação da qualidade da produção intelectual dos programas de pós-graduação no Brasil, aferindo a qualidade dos veículos de divulgação, entre eles os periódicos científicos. Aponta a sua importância, ao enquadrá-los em categorias indicativas de qualidade:

- Representativas da qualidade do veículo - alta (A), média (B), ou baixa (C);

- Relativas ao âmbito de circulação do veículo - internacional (1), nacional (2), local (3).
} 
qualidade estabelecidos pela área de Administração, Ciências Contábeis e Turismo. Esse processo permitiu conceber os indicadores e organizá-los em categorias, agrupando-os de forma lógica, dentro de uma estrutura.

O processo iniciou com reflexões sobre a natureza estocástica dos indicadores e da vinculação indireta entre suas causas e efeitos. Em seguida, um intenso estudo do Documento de Área de Administração, Ciências Contábeis e Turismo, triênio 2007-2009 forneceu elementos para a definição dos critérios de avaliação. Para os propósitos deste estudo, critérios são a essência daquilo que se quer avaliar e que se julga poder esperar legitimamente do processo.

$\mathrm{Na}$ fase seguinte foram definidos os indicadores de desempenho, compreendidos como os mecanismos que descrevem e expressam criteriosamente em que parâmetros avaliar o fluxo editorial e o que avaliar em cada critério definido, no sentido de tornar o processo avaliativo transparente e facilitar o diálogo entre a equipe editorial e a mantenedora. Observando as características a priori e desejáveis que qualquer indicador deve necessariamente exibir, segundo Trzesniak (1998), cada indicador deveria exprimir um aspecto ou uma característica específica do periódico científico que poderia ser mensurada.

Estabelecidos pela equipe editorial, os valores de referência serviram de base para definir os níveis de desempenho que serão aceitáveis ou inaceitáveis para o indicador, a serem alcançados no processo de consolidação do periódico. Configurando-se como metas a alcançar, estabeleceram níveis de qualidade coerentes com as diretrizes expressas pela Área de Administração, Ciências Contábeis e Turismo e pelo corpo diretivo do Senac/SC.

Em linhas gerais, essa categorização consistiu em uma tentativa de organizar os indicadores do universo da comunicação científica com características comuns, que podem, direta ou indiretamente, conter as respostas desejadas e ser monitorados (para fins didáticos, ver no Quadro 1, dois exemplos). 
Quadro 1- Exemplo de estruturação de indicadores do fluxo editorial: critério, indicador, valor de referência.

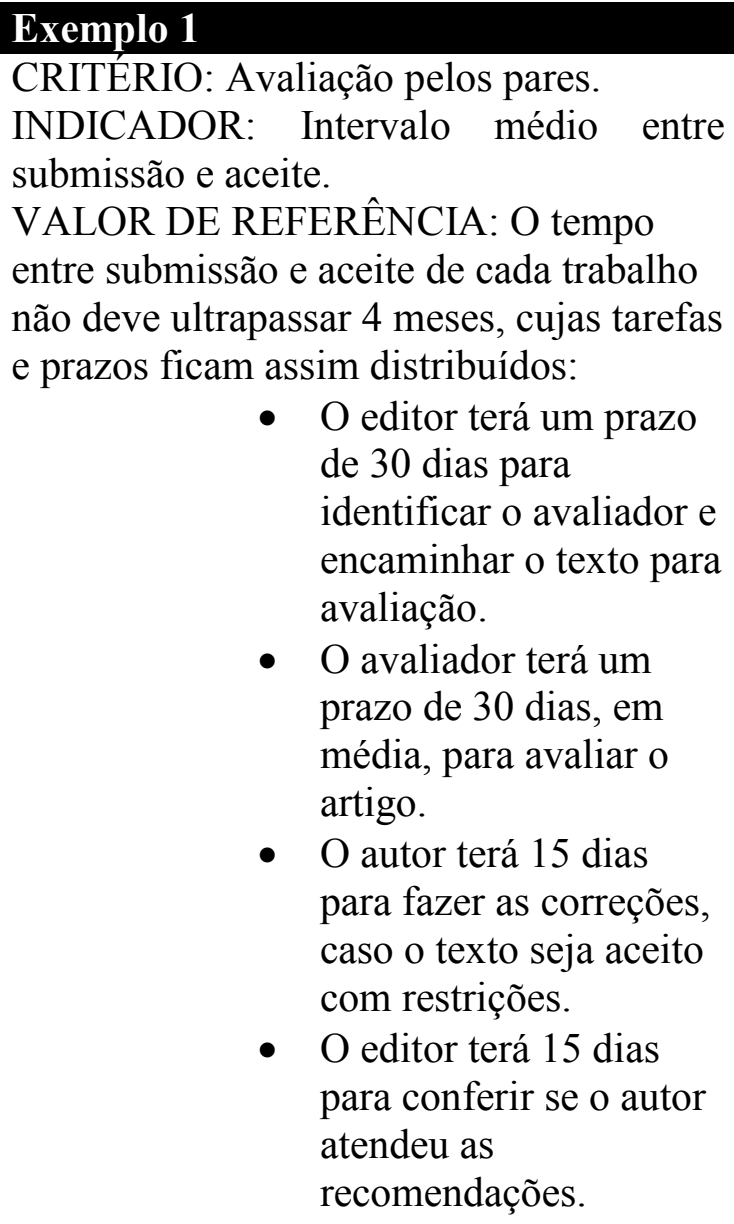

- O editor terá um prazo de 30 dias para identificar o avaliador e encaminhar o texto para avaliação.

- O avaliador terá um prazo de 30 dias, em média, para avaliar o artigo.

- O autor terá 15 dias para fazer as correções, caso o texto seja aceito com restrições.

- O editor terá 15 dias para conferir se o autor atendeu as recomendações.

CRITÉRIO: Avaliação ad hoc.

INDICADOR: Composição do quadro de avaliadores ad hoc.

VALOR DE REFERÊNCIA:

- Mínimo de $80 \%$ de avaliadores vinculados a instituições externas, com diferentes vinculações institucionais de, no mínimo, um por região.

- Nenhuma instituição poderá ter representatividade superior a $20 \%$ entre os avaliadores ad hoc.

- Proporção máxima de duas seções avaliadas por avaliador no período de um ano.

- Proporção mínima de dois avaliadores ad hoc para cada seção do periódico.

- Cadastrar, a cada ano, 10\% de novos avaliadores.

Fonte: elaborado pelas autoras.

Dessa forma, os indicadores e os valores de referência podem ser usados como parâmetros comparativos para avaliar a qualidade de determinado periódico, os objetivos e metas por ele alcançados. A unidade de medida utilizada na mensuração da qualidade representa uma relação entre um resultado e um elemento de referência estabelecido. A inclusão de prazos para os valores de referência também é recomendada; por exemplo: mínimo de $80 \%$ de avaliadores vinculados a instituições externas, com diferentes vinculações institucionais de, no mínimo, um por região, até a $4^{\mathrm{a}}$ edição do periódico, ou até o segundo semestre de 2013. Essa é uma forma de delimitar metas de qualidade da revista.

Assim, a qualidade será alcançada quando um determinado resultado atesta a conformidade de um processo a um padrão previamente estabelecido e convencionado dentro de uma área. A utilização de indicadores, nessa perspectiva, mostra a extensão dos problemas e aponta os elementos necessários à melhoria em cada critério estabelecido. 


\subsection{Proposição de indicadores}

O Quadro 2 apresenta uma proposição de um sistema de indicadores. Como recurso de gestão, esta não pretende ser uma lista exaustiva de indicadores do fluxo editorial, tampouco se pretende apurar a abrangência e a complexidade do que é o dia a dia da gestão de um periódico científico, nem as relações que se estabelecem, entre outras mediações que entram em ação nesse processo.

Quadro 2 - Proposição de um sistema de indicadores do fluxo editorial do periódico científico

\section{Critérios Indicadores}

\begin{tabular}{|l|l} 
Classificação Qualis & Estrato de classificação do periódico no triênio. \\
\hline Adequação tecnio
\end{tabular}

\begin{tabular}{l|l}
\hline Adequação técnico- & Proporção de fascículos atendendo às normas e
\end{tabular}

normativa do periódico. especificações estabelecidas no regulamento do periódico.

Qualidade editorial: $\quad$ Proporção de seções dos fascículos atendendo à finalidade do aderência dos temas periódico, enunciada e sintetizada na sua missão, foco e das seções à área escopo.

temática do periódico, Proporção de seções (artigos de pesquisa, originais e preservando a missão, inéditos, resenhas, relatos de pesquisa etc.), por volume.

foco e escopo do periódico; coerência das seções do periódico com a linha editorial.

Avaliação pelos pares $\quad$ Composição do quadro de avaliadores ad hoc:

- Percentual de seus integrantes vinculados a instituições externas, com diferentes vinculações institucionais de, no mínimo, um por região.

- Percentual de representatividade institucional entre os avaliadores ad hoc.

Quantidade de artigos avaliadas por avaliador no período de um ano.

Quantidade de avaliadores ad hoc para cada seção do periódico.

Percentual de novos avaliadores cadastrados em cada período de um ano.

Conselho Editorial e

Composição do conselho editorial e do conselho científico:

Conselho Científico

- Percentual de seus integrantes vinculados a instituições externas do Brasil.

- Percentual de representantes de instituições estrangeiras.

- Percentual de unidades da federação representadas no conselho.

- Percentual de artigos de autores filiados a instituições estrangeiras.

- Percentual de artigos de autores filiados a instituições externas (não incluídos os que tenham autoria estrangeira). 


\begin{tabular}{|l|l|}
\hline & $\begin{array}{l}\text { Percentual de autores com titulação de doutor, mestre, } \\
\text { especialistas e discentes (graduação e pós-graduação). } \\
\text { Percentual de autores vinculados à instituição } \\
\text { patrocinadora do periódico. }\end{array}$ \\
\hline Periodicidade & $\begin{array}{l}\text { Proporção de edições lançadas na data prevista no } \\
\text { regulamento. }\end{array}$ \\
\hline $\begin{array}{l}\text { Regularidade das } \\
\text { edições }\end{array}$ & Intervalo médio entre submissão e aceite. \\
\hline Qualidade científica & $\begin{array}{l}\text { Percentual dos trabalhos avaliados e aprovados para } \\
\text { publicação, com ou sem restrições. }\end{array}$ \\
\hline Perenidade & $\begin{array}{l}\text { Tempo de publicação, para medir a continuidade da } \\
\text { publicação científica. }\end{array}$ \\
\hline Visibilidade & $\begin{array}{l}\text { Índice de acessos no ano. } \\
\text { Índice de cadastro de novos leitores no ano. } \\
\text { Número de indexações nos repositórios e/ou catálogos de } \\
\text { bibliotecas no ano. } \\
\text { Número de indexações em bases de dados nacionais e } \\
\text { estrangeiras recomendadas pela área. } \\
\text { Índice de visibilidade em sítios de busca (Page Rank) entre } \\
\text { as edições. } \\
\text { Índice de fator de impacto no triênio. }\end{array}$ \\
\hline
\end{tabular}

Fonte: Elaborado pelas autoras, com base no Documento de Área de Administração, Ciências Contábeis e Turismo (BRASIL, 2009).

O fator de impacto, apresentado no Quadro 2 como um indicador do critério "visibilidade", vem se constituindo como uma das mais expressivas formas para medir o resultado dos esforços empreendidos na gestão dos peródicos científicos, pois reflete a média de citações dos artigos publicados em determinada revista. Foi criado por Eugene Garfield, fundador do Institute for Scientific Information (ISI), com o objetivo de funcionar como um parâmetro de qualidade. O Journal Citation Reports (JCR), do Thomson Reuters, publica a lista do fator de impacto das revistas.

Da mesma forma, a indexação do periódico em bases de dados nacionais e internacionais também vem se constituindo como uma medida de qualidade internacional e como um dos principais indicadores de visibilidade do periódico. Entretanto, em ambos os casos, o resultado somente será alcançado à medida que os demais critérios apontados no Quadro 2 forem atendidos, os quais são: qualidade editorial, qualidade científica, corpo editorial, regularidade de publicação, normalização e periodização.

Não obstante, a gestão do periódico científico, assim como qualquer outro sistema de gestão, requer habilidade para compreender, reconhecer e gerenciar todas as relações que se estabelecem e que entram em ação nesse processo. 


\subsection{Formalização dos indicadores}

Os indicadores formulados e formalizados foram objeto de registro em documento próprio, denominado de Regulamento do Periódico Científico do Senac/SC, e depois de homologados em nível de instância de decisão, foram disseminados para toda a equipe editorial. Atualmente funcionam como recurso de gestão, não somente como recurso de avaliação ad hoc, mas principalmente como norteadores de padrões e metas na gestão do fluxo editorial.

\section{CONCLUSÃO}

Para funcionar como recurso de gestão, o propósito do indicador é, em última instância, orientar as ações que deverão ser empreendidas, contribuindo para a gestão sistêmica e racional do fluxo editorial. Isso significa que a avaliação precisa, antes de tudo, auxiliar na identificação e na formulação de políticas e ações de melhorias em relação às insuficiências diagnosticadas.

Assim, a função da avaliação, antes de tudo, é coletar evidências significativas e fornecer à equipe editorial informações necessárias e bases para a tomada de decisão em relação à melhoria do processo editorial, oferecendo condições de acompanhar e monitorar seus próprios resultados, com vistas a alcançar níveis de qualidade compatíveis com os padrões da área na qual o periódico está inserido.

A principal característica de um indicador é a sua capacidade de sintetizar um conjunto de informações, representando apenas o significado essencial dos aspectos analisados. Todavia, definir um indicador pode também simplificar em demasia o processo de gestão do fluxo editorial, ignorando, assim, a rica complexidade do sistema. Indicadores não são realidades, apenas representações ou abstrações da realidade nas mentes das pessoas.

Os indicadores propostos, objeto da análise, exibem as características a priori e desejáveis evidenciadas por Trzesniak (1998). Entretanto, muita precaução é necessária, pois os indicadores estocásticos fornecem um grau de controle menor se comparados a uma situação determinística. Portanto, na proposição de indicadores buscam-se aspectos da gestão dos periódicos científicos com características específicas que contenham as respostas desejadas, orientando decisões e ações que, efetivamente, serão suportadas pela interpretação dos resultados. 
As considerações acima levam a crer que estabelecer os indicadores para as ciências humanas e sociais se constitui em um considerável desafio. No processo de gestão do fluxo editorial, o número e a complexidade dos fatores em questão tornam difícil reconhecê-los com exatidão e então monitorá-los. Entretanto, se bem integrados e ajustados ao contexto a ser avaliado, contribuirão para a gestão dos periódicos. 


\section{REFERÊNCIAS}

BARBALHO, C. R. S. Periódico científico: parâmetros para avaliação de qualidade. In: FERREIRA, Sueli M. S. P.; TARGINO, Maria das Graças (Orgs.). Preparação de revistas científicas, São Paulo: Reichmann \& Autores, 2005. p.123-158.

BRASIL. Ministério da Educação. Coordenação de Aperfeiçoamento de Pessoal de Nível Superior. Documento da área Administração, Ciências Contábeis e Turismo 2009. Disponível em:

$<$ http://www.capes.gov.br/images/stories/download/avaliacao/ADMIN17jun10.pdf $>$. Acesso em: 01 abr. 2012

CAMARGO, L. L. de. Uso de indicadores da qualidade para o gerenciamento estratégico de empresas do ramo comercial. 2000. Dissertação (Mestrado em Engenharia de Produção) - Departamento de Engenharia da Produção e Sistemas, UFSC, Florianópolis, 2000. Disponível em: <

http://biblioteca.universia.net/html_bura/ficha/params/id/595942.html>. Acesso em 30 mar. 2012.

FACHIN, G. R. B.; HILLESHEIM, Araci I. de A. Periódico científico: padronização e organização. Florianópolis: Ed. UFSC, 2006.

FERREIRA, S. M. S. P.; TARGINO, Maria das Graças. Acessibilidade e visibilidade de revistas científicas eletrônicas. São Paulo: Ed. Senac São Paulo, 2010.

FISCHMAN, G. E. Algunos desafios y oportunidades para fortalecer las publicaciones acadêmicas em América Latina. In: ENCONTRO NACIONAL DE USUÁRIOS DO SEER, 1, UFSC, 2010. Anais eletrônico...Disponível em: < http://seer.ibict.br/images/stories/GEFEUSEER2010.pdf>. Acesso em: 01 abr. 2012.

GIL, A. C. Como elaborar projetos de pesquisa. 4. ed. São Paulo: Atlas, 2007.

MARTINS, G. de A.; THEÓPHILO, C. R. Metodologia da investigação científica para ciências sociais aplicadas. 2.ed. São Paulo: Atlas, 2009.

MUELLER, S. P. M. A comunicação científica e o movimento de acesso livre ao conhecimento. In: SIMPÓSIO SOBRE A COMUNICAÇÃO CIENTÍFICA: desafios da inclusão digital. UFSC, 2003. Anais eletrônico... Disponível em:

$<$ http://www.periodicos.ufsc.br/index.php/eb/article/view/356/374>. Acesso em: 30 maio 2011.

PALADINI, E. P. Avaliação estratégica da qualidade. São Paulo: Atlas, 2002.

STUMPF, Ida Regina Chitto. Passado e futuro das revistas científicas. Ciência da Informação, Brasília, v.25, n. 3, 1996. Disponível em:

$<$ http://capim.ibict.br/index.php/ciinf/article/view/463/422 >.Acesso em 26 mar. 2012.

TAKASHINA, N, T. Indicadores da Qualidade e do Desempenho. Rio de Janeiro: Qualitymark, 1999. 
THILOLLENT, M. Metodologia da pesquisa-ação. São Paulo: Cortez, 1985.

TRZESNIAK, P. Indicadores quantitativos: reflexões que antecedem seu estabelecimento. Ciência da Informação, Brasília, v.27, n. 2, p. 159-164, maio/ago. 1998. Disponível em: $<$ http://www.scielo.br/pdf/ci/v27n2/2729808.pdf>. Acesso em 30 mar. 2012. 